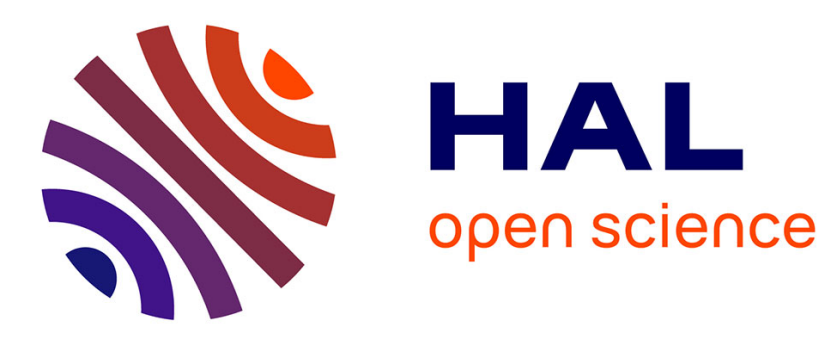

\title{
Investigation of moisture transport properties of cementitious materials
}

Zhidong Zhang, Mickaël Thiery, Véronique Baroghel-Bouny

\section{To cite this version:}

Zhidong Zhang, Mickaël Thiery, Véronique Baroghel-Bouny. Investigation of moisture transport properties of cementitious materials. Cement and Concrete Research, 2016, 89, pp.257 - 268. 10.1016/j.cemconres.2016.08.013 . hal-01622017

\section{HAL Id: hal-01622017 \\ https://hal-enpc.archives-ouvertes.fr/hal-01622017}

Submitted on 23 Oct 2017

HAL is a multi-disciplinary open access archive for the deposit and dissemination of scientific research documents, whether they are published or not. The documents may come from teaching and research institutions in France or abroad, or from public or private research centers.
L'archive ouverte pluridisciplinaire HAL, est destinée au dépôt et à la diffusion de documents scientifiques de niveau recherche, publiés ou non, émanant des établissements d'enseignement et de recherche français ou étrangers, des laboratoires publics ou privés. 


\title{
Investigation of moisture transport properties of cementitious materials
}

\author{
Zhidong ZHANG ${ }^{1, a}$, Mickaël THIERY ${ }^{\mathrm{b}, *}$, Véronique BAROGHEL-BOUNY ${ }^{\mathrm{a}}$ \\ ${ }^{a}$ Paris-Est University, IFSTTAR, MaSt/FM²D, F-77447 Marne la Vallée, France \\ ${ }^{b}$ DGAC, STAC, F-94385 Bonneuil-sur-Marne, France
}

\begin{abstract}
Moisture transport in cementitious materials is directly related to the durability of concrete structures. When the material loses moisture, the drying shrinkage induces cracks which are harmful to the solid body. When liquid moves into the material, it can carry aggressive ions. Hence, moisture transport properties are important to cope with durability issues. The present paper is focused on two ways to enhance our understanding of moisture transport properties of cementitious materials. They are based on the indirect determination of the liquid water permeability and water vapour diffusion coefficient. The first one is known as the "inverse analysis" method. In a moisture transport model, the liquid permeability and diffusion coefficient can be adjusted in order to fit the measured mass loss curves and water content profiles. In the second way, measured apparent diffusion coefficient (also called moisture diffusivity) curves are fitted over a large range of relative humidity (RH) by a general expression which includes both liquid transport and vapour diffusion. Due to different RH ranges of predominance of liquid and vapour transport, the liquid water permeability and vapour diffusion coefficient can be determined separately. Input experimental data on cement pastes are collected from the literature. Discussions on relative permeability and Knudsen diffusion show a significant influence on modelling of moisture transport. A further comparison with measured permeability data is able to provide a better understanding of moisture transport properties.
\end{abstract}

Keywords: cement paste (E), moisture transport (C), diffusion coefficient (C), liquid water permeability (A), inverse analysis (B), Knudsen effect (A)

\section{Introduction}

The durability of concrete structures is always closely related to the moisture properties in the cementitious material. Liquid water in contact with concrete may contain different aggressive agents, such as chloride ions, which can penetrate through the concrete cover and corrode the rebars. For this reason, moisture transport is a crucial theme when evaluating the durability.

Under saturated conditions, Darcy's law is sufficient to describe moisture transport in porous materials, i.e.

$$
J_{l}=-\rho_{l} \frac{k}{\eta} \nabla P_{l}
$$

where $J_{l}\left(\mathrm{~kg} \cdot \mathrm{m}^{-2} \cdot \mathrm{s}^{-1}\right)$ is the liquid flux, $\rho_{l}\left(\mathrm{~kg} \cdot \mathrm{m}^{-3}\right)$ is the density of liquid water, $k\left(\mathrm{~m}^{2}\right)$ is the liquid permeability, $\eta(\mathrm{Pa} \cdot \mathrm{s})$ represents the dynamic viscosity of liquid water and $P_{l}(\mathrm{~Pa})$ is liquid pressure.

In most cases, the material is not fully saturated with water. Buckingham considered that Darcy's law is still applicable for unsaturated solids [1], so Eq. (1) can be written as:

$$
J_{l}=-\rho_{l} k_{r l} \frac{K_{l}}{\eta} \nabla P_{l}
$$

\footnotetext{
${ }^{*}$ Corresponding author. E-mail address: mickael.thiery @ aviation-civile.gouv.fr (M. Thiery)

${ }^{1}$ Present address: Department of Civil and Environmental Engineering, Princeton University, Princeton, NJ 08544, USA
} 
In Eq. 22], apparent water permeability $k_{r l} K_{l}$, consisting of the liquid water permeability $K_{l}$ and the relative permeability $k_{r l}$, is a crucial factor for the modelling of moisture transport. Generally, $k_{r l}$ is considered as a function of the liquid water saturation $S$ (ratio between liquid water volume and voids volume). The liquid water permeability $K_{l}$ is usually determined from experimental data.

Conventional methods to measure $K_{l}$ were carried out on fully saturated materials. In these kinds of measurements, the sample must be sealed, so that liquid water is only injected from one face by applying extra pressure and leaks from the opposite face. When the flow in the porous body reaches steady state, the flow rate is then used to calculate permeability $K_{l}$ according to Darcy's law [2, 3, 4, 5, 6].

Indirect methods are also used to measure liquid water permeability of cementitious materials. For instance, the beam bending (BB) method is one of rapid and indirect methods [7, 8, 9] which was originally developed for soft gels and later was applied to cementitious materials. This method is based on the principle of exerting a certain strain to a long and slender sample to obtain a relaxation curve, which is considered including both hydrodynamic and viscoelastic effects. By fitting this relaxation curve, $K_{l}$ can be determined. This method has very clear requirements for the geometry of the sample which makes it less applicable for concretes due to needing inconveniently large samples to avoid the influences of aggregates. A method so-called thermopermeametry (TPA) was also introduced to cementitious materials on the basis of research about gels [10, 11, 12, 13]. If assuming that the thermal expansion of liquid is always much greater than that from the solid phase, this method can estimate $K_{l}$ by measuring the amount of liquid water which flows out of the material because of the thermal expansion. This method is very sensitive to saturation conditions, and the presence of air voids or entrapped air in non-fully saturated materials may have a great influence on the measured results. Water-sealed curing is thus generally considered as a way to avoid this shortcoming even if the dissipation of entrapped air created by self-desiccation remains extremely difficult [14]. The dynamic pressurization (DP) can reduce the effect of air voids by keeping the sample in a sealed vessel and gradually increasing or decreasing pressure [15, 16]. If repeating the pressure cycles, the residual air in the material can be slowly dissipated. However, under high external hydrostatic pressure mechanical deformation may occur over a long period and the solid skeleton can be damaged during depressurization.

Beside of experimental measurements, permeability can be inferred by using information related to the geometry and morphology of the microstructure such like pore size distribution, porosity, tortuosity, connectivity, etc. Based on mercury intrusion porosimetry (MIP) data for the assessment of the percolation radius of the microstructure and resistivity measurements to determine the formation factor (inversely proportional to the product of porosity and tortuosity), the Katz-Thompson model [17] (K\&TI model) has been proven as relevant for estimating the permeability of sedimentary rocks. Another version of this model is also proposed in [17]; it permits to avoid the use of resistivity measurements by assessing the formation factor only by mercury intrusion (K\&TII model). Baroghel-Bouny et al. [18] showed that the K\&TI relationship slightly overestimates the permeability for concretes and mortars. The investigations of K\&TII performed by El-Dieb and Hooton [3] illustrated that this model leads to a more pronounced overestimation; the correlation can even be quite low for cementitious materials. The main reason is that in a MIP measurement the sample must be totally dried. As it has been pointed out in the literature, microstructure of the material is altered whatever the selected method of drying pre-treatment (oven-drying, vacuum drying, freezing drying or solvent exchange) [19]. Supercritical drying can be considered as a better drying method to preserve the microstructure [19, 20]. Halamickova et al. [21] pointed out other arguments. They suggested that the Katz-Thompson relations may work better for systems with highly interconnected capillary pore networks than for systems where the fine nanostructure of gel pores dominates the transport as it is the case in most cement-based materials. From this point of view, therefore, the calculated permeability by the Katz-Thompson models may be overestimated. Indeed, as originally explained by Katz and Thompson, their theory is valid for materials with large pores and mono-modal pore size distribution [22] centered on the capillary range.

When the cementitious material is exposed to a unsaturated condition, pores inside the material are partially saturated, which means that not only liquid water transport occurs in the pore network, but also water vapour diffuses in the space without liquid. A diffusion equation (with potential $\rho_{v}$ the density of water vapour) should thus be added to describe the vapour diffusion contribution in the moisture transport.

$$
J_{v}=-D \nabla \rho_{v}=-D_{0} f \nabla \rho_{v}
$$


where $J_{v}$ is the flux of water vapour, $D$ represents vapour diffusion coefficient $\left(\mathrm{m}^{2} \cdot s^{-1}\right)$ and $D_{0}$ is the free vapour diffusion coefficient in the air. The symbol $f$ stands for the resistance factor of pore network for gaseous diffusion (see below).

In order to perform the simulation of moisture transport in unsaturated materials, $f$ in Eq. (3) must be known in addition to the liquid water permeability. The resistance factor $f$ is commonly considered as a function of saturation $S$. If there is more liquid water in the pore network, the resistance effect to vapour diffusion should be larger; thus, $f$ is a monotonically decreasing function of $S$. The exponential equation $(f(S)=\exp (-\kappa S), \kappa>0,[23,24])$ or the reciprocal function $(f(S)=1 /(1+\kappa S), \kappa>0$, based on [25, 26]) are commonly used to calculate $f$. However, diffusion in porous materials is not only affected by saturation but also by microstructure properties such as connectivity and tortuosity. An equation proposed by Millington [? ] takes into account both effects. It has been further reinterpreted in the literature [27] and given as:

$$
f(S, \phi)=\phi(1-S) \cdot \phi^{x_{D}-1}(1-S)^{x_{D}+1}
$$

where $x_{D}$ is a material parameter. The term $\phi(1-S)$ stands for the actual space available for vapour diffusion. The term $\phi^{x_{D}-1}(1-S)^{x_{D}+1}$ represents the tortuosity and connectivity effects to some extent.

Here, the problem of determining $f$ turns into how to find a proper value for $x_{D}$. Millington [?] demonstrated $x_{D}=4 / 3$ for granular media like soils, which are much more porous than cementitious materials. In the study performed on concrete and mortar by using data based on diffusion of $\mathrm{O}_{2}$ and $\mathrm{CO}_{2}$, Thiéry et al. [27] suggested $x_{D}=2.74$. Due to the lack of experimental data for water vapour, in our previous studies 2.74 was used for modelling of moisture transport. But, apparently, this choice is inappropriate because water vapour behaves differently to $\mathrm{O}_{2}$ or $\mathrm{CO}_{2}$ in a narrower pore network than granular media. Additionally, different cementitious materials have different characteristics of connectivity and tortuosity.

The relative permeability $k_{r l}$ used in Eq. (2) has a key role in the description of moisture transfers in cementitious materials. However, $k_{r l}$ can not be directly measured, unlike the relative permeability to gas $\left(k_{r g}\right)$ for which researches have exhibited relevant relationships [27]. Regarding $k_{r l}$, the difficulty relies on the principle that both advection of liquid-water and diffusion of water vapour occur in experiments involving moisture transfers (sorption experiments, cup tests, etc.). To face this difficulty, many authors have proposed empirical relationships of apparent diffusivity $v s$. RH or liquid water saturation. The most famous is the one proposed by Bažant and Najjar [28]. This kind of relation provides the description of moisture transfers through a unique Richards-type equation which aggregates liquid water advection and water vapour diffusion. For a durability prediction purpose, it can however be necessary to distinguish both flows (for the prediction of carbonation or chloride ingress for example). In the literature, as far as we are aware, only theoretical models for $k_{r l}$ exist. They generally correspond to models initially proposed in petroleum research. We have selected two of those models which are broadly used in the field of transport phenomena in porous media and we propose to discuss their relevancy in the present discussion.

Even though various methods have already been proposed to determine the two unknowns $K_{l}$ and $x_{D}$, this paper will elaborate two specific methods: one is known as "inverse analysis" and the other one is based on the fitting of the measured apparent diffusion coefficient curve ( $v s$. saturation $\mathrm{S}$ ). These two methods use the same moisture transport model while they need different input data. The aims of the present study are thus to investigate that: (1) if we use the same formulas but different input data, can we obtain similar results for moisture transport properties? 2) how can other factors affect moisture transport properties? Although these two methods can be used to determine both liquid permeability and diffusion coefficient by fitting measured data, the present paper does not attempt to claim that they are better than other methods for the determination of moisture transport parameters. For implementations of these methods, available data from the literature will be used.

The "inverse analysis" method uses a moisture transport model to fit measured data, such as mass loss curve (generally, the drying kinetics). The transport parameter $K_{l}$ is the only unknown parameter in the model, and thus can be inferred. Note that drying kinetics can also be fitted by various empirical equations which have no physical meaning. For example, a non-equilibrium mass loss curve can be formulated by a polynomial or be well fitted by Weibull equation, a modified exponential equation [29]. Nevertheless, the parameters in these empirical equations are not associated with any transport property. By using the model proposed in [30, 31], researchers have already employed "inverse analysis" method to determine the liquid water permeability $K_{l}$ for cementitious materials [32, 33, 34]. To 
investigate the performance of the model to describe moisture transport within the material, it is possible to use additional data of second order like profiles. In the present work, the saturation profiles measured by Gamma-ray attenuation are chosen to go further in the validation of the "inverse analysis" method. Furthermore, by adjusting $x_{D}$ the fitting of saturation profiles can be improved. This provides a new way to determine $x_{D}$.

Another way to investigate moisture properties is to fit the measured apparent diffusion coefficient curve $v s$. relative humidity $(\mathrm{RH})$ or liquid water saturation $(S)$. This curve is generally obtained through the mass loss curve for various small RH ranges [35], generally in the framework of the determination of the de-adsorption water vapour isotherm. If considering that moisture transport is a diffusion process, Fick's second law (or $S$-based form of Richards' equation) is able to describe it. The diffusion coefficient (also known as apparent diffusion coefficient or diffusivity coefficient) includes both liquid water transport and water vapour diffusion. Using one function for apparent diffusion coefficient (it must contain liquid permeability $K_{l}$ and the material parameter $x_{D}$ ) to fit the measured values, both $K_{l}$ and $x_{D}$ can be obtained by considering ranges of RH where moisture transport is governed either by liquid water transport, or water vapour diffusion.

Hence, regarding the structure of this paper, the basic characteristics of the used moisture transport model will be first introduced, followed by theories and results from "inverse analysis" and fitting apparent diffusion coefficient curve. In the Discussion Section, two factors, relative permeability and Knudsen effect, are considered in particular due to their high influence on the determination of $K_{l}$ and/or $x_{D}$.

\section{Moisture transport model}

Either for "inverse analysis" or fitting diffusion coefficient to determine the liquid permeability $K_{l}$ and diffusion coefficient (more precisely, $x_{D}$ in the present paper), an efficient moisture transport model has to be chosen. Moisture transport in a partially saturated porous medium like cementitious materials is mainly governed by the transport of three phases, such as liquid water, water vapour and dry air. In a previous study, it has been shown that dry air has very low contribution to mass transport and only causes fluctuated air pressure in the material [36]. This conclusion was also drawn by the asymptotic analysis performed by Coussy and Thiéry [37, 38]. Besides, considering that the liquid phase remains incompressible and total gas pressure constant, the two mass balance equations of liquid water and water vapour can be represented by a simplified equation regarding moisture, i.e. including liquid water and vapour. Mainguy et al. [33] further simplified the model for specific conditions, by considering only liquid water and neglecting the vapour diffusion. They found that such a model can give very similar liquid water permeability value compared with the three-phase model. As pointed out by the authors, this simplified approach is suitable for the case of drying of low permeable materials which are initially close to saturation and exposed to a high RH boundary condition. In that situation, liquid water governs mass transport [36], while in a lower RH range vapour diffusion becomes not negligible. More details about this topic will be discussed in Section 4 . The model selected here for "inverse analysis" method includes the transport of both liquid water and water vapour. Combining Eq. (2) and Eq. (3) with mass balance principles to derive a governing equation for unsaturated moisture transport yields the following mass balance equation (in 1D form, Richards-type):

$$
\frac{\partial S}{\partial t}=\frac{1}{\phi \rho_{l}} \frac{\partial}{\partial x}\left(J_{l}+J_{v}\right)=\frac{\partial}{\partial x}\left(-k_{r l}(S) \frac{K_{l}}{\phi \eta} \frac{\partial P_{l}}{\partial x}-\frac{D_{0} f(S, \phi)}{\phi \rho_{l}} \frac{\partial \rho_{v}}{\partial x}\right)
$$

The equilibrium between liquid water and water vapour is assumed in this model. The difference between the gas pressure and the liquid phase pressure $\left(P_{c}=P_{g}-P_{l}\right)$ is defined as a capillary pressure governed by Kelvin's equation. Thus, for a given material, a characteristic capillary pressure curve representing the relationship $P_{c} v s . S$ exists for the main drying process (no hysteresis is taken into account). In the case of cementitious materials, this curve can be derived from the measured water vapour sorption isotherms [39]. In this study, the capillary pressure curve is expressed by the well-known two-parameter van Genuchten equation [40] which has been applied to cementitious materials [33] and proved to be a simple and easy-to-use formula [41]:

$$
P_{c}(S)=a\left(S^{-1 / m}-1\right)^{1-m}
$$


where $a(\mathrm{~Pa})$ and $m(-)$ are two fitting parameters.

To solve Eq. [5], another important transport coefficient is the relative permeability $k_{r l}$. Following previous studies [33, 20], the van Genuchten-Mualem equation (denoted by VGMa in the present paper) [40] in a simple analytical form is employed here, as follows.

$$
k_{r l}(S)=S^{\ell}\left[1-\left(1-S^{1 / m}\right)^{m}\right]^{2}
$$

where parameter $m$ is taken from Eq. (6). The term $S^{\ell}$ is a correction factor, which accounts for the influence of tortuous effects of pores on the liquid transport. Mualem suggested $\ell=0.5$ for most porous materials. This value has also been used for cementitious materials [33, 42, 43].

The interaction between the material and the external environment, directly affecting the moisture evaporation from the material surface, must be taken into account. Moisture content gradient takes place in the air in the vicinity of the exposed surface of cementitious materials (the so-called boundary layer). This gradient is all the more important that the material is close to saturation which makes the Dirichlet-type boundary condition (RH is imposed) irrelevant. The presence of an external moisture gradient governs the moisture flux from the inner part of the material to its surroundings. An expression which takes into account this gradient has been used in the literature (known as fluxconvective or Neumann boundary condition) [44, 45]. It provides an expression of the mass flux of moisture as follows:

$$
\left.\left(J_{l}+J_{v}\right)\right|_{x=0}=\phi S E\left(P_{v}^{0}-P_{v}^{e}\right)
$$

This boundary condition will be chosen for the present study. It includes the material property (porosity $\phi$ ), moisture state in the ambient environment (external vapour pressure $P_{v}^{e}$ ), moisture state in the material near the surface $\left(P_{v}^{0}\right.$ and saturation $S$ ) and the interactions between the ambient environment and the material. The emissivity $E$ varies with external conditions, such as air convection and temperature $T$. For laboratory conditions (no air flow and $T=23 \pm 1^{\circ} \mathrm{C}$ ), the measured $E$ is $2.58 \times 10^{-8} \mathrm{~kg} \cdot \mathrm{m}^{-2} \cdot \mathrm{s}^{-1} \cdot \mathrm{Pa}^{-1}$ [46, 44]. The term $\phi S$ takes into account the reduction of the unsaturated material exposed to the environment.

\section{Inverse analysis}

\subsection{Theory}

If using the above moisture transport model to perform simulation of drying experiments, we need the input data related to the sorption isotherms which must be measured thanks to specific experiments and fitted by Eq. (6) to determine parameters $a$ and $m$. There are still two unknowns: $K_{l}$ and $f$ (more precisely $x_{D}$ ) in Eq. (5). In the literature, the value of $x_{D}$ is either set as 4/3 [33] or as 2.74 [47, 48, 49]; thus, in the model $K_{l}$ is the sole unknown and can be determined by fitting the measured mass loss curve from the drying experiment. However, as mentioned in the Introduction, these $x_{D}$ values are questionable since not yet verified for vapour diffusion in cementitious materials. The present study therefore intends to let $x_{D}$ be another free parameter, meaning that another set of measured data are needed. The measured saturation profiles are chosen in this paper to contribute to the fitting of $x_{D}$.

\subsection{Experimental data and fitting results}

The experimental data used in the present paper were collected from literature [39] and [44]. Three cement pastes with different water-to-cement ratios were used to verify the described model. The material properties are gathered in Table 1. They are made from the same OPC cement (CEM I 52.5, according to EN 197-1 European standard).

All cement pastes were cast in $7 \mathrm{~cm}$-diameter cylindrical moulds. Prior to dying experiments, specimens had been sealed for more than 200 days to reach chemical stabilization. RH after the self-desiccation, shown as "Initial RH" in Table 11. has been measured by means of sensors embedded in dedicated specimens [44]. After demoulding, cylinders were cut into around $10 \mathrm{~cm}$-length specimens, and the circumferential surface and one end of the specimen were sealed with self-adhesive aluminium foil sheets. The other end was open for moisture exchanges with ambient environment. Thus unidirectional moisture transfer was ensured. All specimens were stored in desiccators for drying experiments 
Table 1: Properties of materials collected from literature [39] and [44].

\begin{tabular}{llll}
\hline Materials & w/c & Porosity & Initial RH (\%) \\
\hline Paste1 & 0.35 & 0.31 & 83 \\
Paste2 & 0.45 & 0.41 & 89 \\
Paste3 & 0.60 & 0.49 & 95 \\
\hline
\end{tabular}

at room temperature $\left(T=23 \pm 0.1^{\circ} \mathrm{C}\right)$ and $\mathrm{RH}^{e}=53.5 \%$ fixed by using a saturated salt solution of magnesium nitrate). The mass loss curves were measured by weighing specimens at different specific times. Saturation profiles were regularly assessed based on the density changes measured by gamma-ray attenuation [50, 44]. Note that drying experiments were not performed on water-saturated samples, but on samples whose initial moisture content is representative of self-desiccation conditions. The porosity values (provided in Table 1 ) were measured on dedicated specimens (after the same sealed-curing period) according to procedure based on vacuum-saturation (72 hours), hydrostatic weighing and drying at $105^{\circ} \mathrm{C}$ until mass stabilization [44]. Desorption isotherms were measured by the mean of saturated salt solutions [39] and fitted according to Eq. 6] to determine parameters $a$ and $m$.

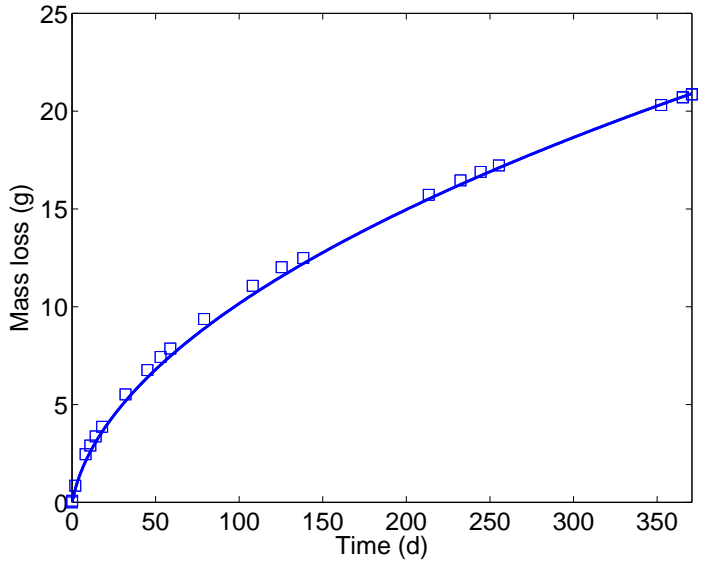

(a) Mass loss curve

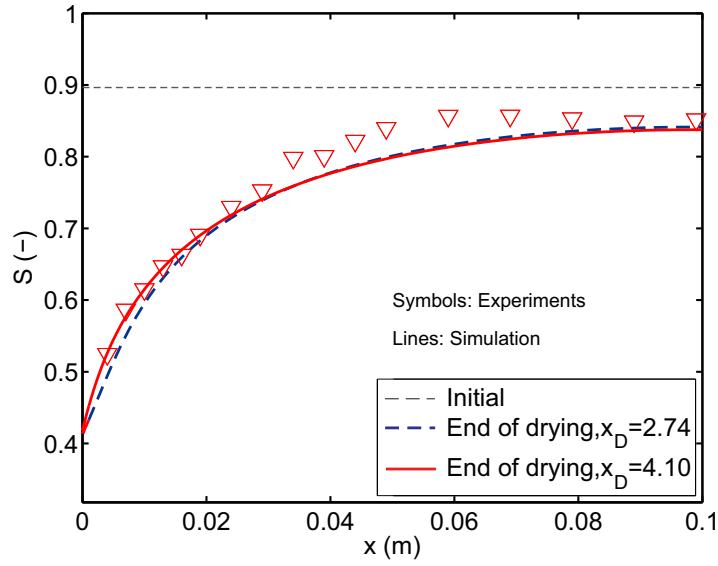

(b) Saturation profile

Figure 1: Comparison of calculated (a) mass loss curve and (b) saturation profile at the end of drying with measured data for Paste2. Note that the saturation profile "End of drying" should correspond to the last measured data in (a), which is about 371 days drying.

The drying kinetics (mass loss curves) and saturation profiles were used to fit the liquid permeability $K_{l}$ and material parameter $x_{D}$ representing diffusion in Eq. (4). The numerical implementation of Eq. (5) was done by the finite difference method in spacial discretization and backward Euler method in time step (see details in [20]). The mass loss was calculated by integrating the mass transfer through the boundary (Eq. 8) over the cross-section. Qualitatively, we found that $K_{l}$ plays the main role for the calculation of mass loss curves while $x_{D}$ has very limited influence. This is in agreement with results in previous studies where the mass loss curves were generally used to inversely determine $K_{l}[32,33,34,51,18,36,20]$. Adjusting the value of $x_{D}$ can however improve the shape of saturation profiles determined by gamma-ray attenuation (see Fig. 1 1 ). Consequently, the following fitting procedure has been adopted here. First, we let $x_{D}=2.74$ (commonly-used value in previous studies [27, 34, 51, 18, 36, 20]) to fit the measured drying kinetics by adjusting $K_{l}$. Second, we change the value of $x_{D}$ to optimize the fitting of gamma-ray saturation profile at a given time of drying. Then, the new $x_{D}$ value is used to fit the mass loss curve again and a new $K_{l}$ is obtained. One fitting result for Paste2 is shown in Fig. 1. Fitted $K_{l}$ and $x_{D}$ for the selected materials are given in Table 2. The values of the coefficient of determination $\left(R^{2}\right)$ for both curves are quite close to 1 , meaning very good fitting.

Table 2 shows that $x_{D}$ values for selected materials are greater than 2.74 which was the value used in our previous studies. This can support the hypothesis that $x_{D}=2.74$ may not be relevant as it was recalled in the Introduction. It 


\begin{tabular}{lllllll}
\multicolumn{7}{c}{ Table 2: Fitting results from inverse analysis of drying kinetics and gamma-ray profiles. } \\
\hline Materials & $K_{l}\left(\times 10^{-21}\right.$ & $\left.\mathrm{m}^{2}\right)$ & $K_{l}\left(\times 10^{-21}\right.$ & $\left.\mathrm{m}^{2}\right)$ & $x_{D}(-)$ & $R^{2}$ (mass loss) \\
& $\left(x_{D}=2.74\right)$ & $\left(x_{D}\right.$ adjusted $)$ & & & $R^{2}$ (profile) \\
\hline Paste1 & 0.46 & 0.51 & 3.95 & 0.99 & 0.92 \\
Paste2 & 2.00 & 2.15 & 4.10 & 0.999 & 0.93 \\
Paste3 & 32.0 & 36.0 & 4.50 & 0.98 & 0.96 \\
\hline
\end{tabular}

also confirms that the value initially proposed by Millington is far too low $\left(x_{D}=4 / 3\right)$, meaning that vapour diffusion in cementitious materials encounters much higher resistance effects than in granular media. Compared to previous results [20], the new $K_{l}$ values determined according to this 3-step iterative procedure are slightly increased. The explanation is that the contribution of liquid water must be increased to compensate the mass change for the decreasing contribution of water vapour in the total mass transport caused by greater values of $x_{D}$. Indeed, Fig. 2 clearly shows that a larger value of $x_{D}$ provides a smaller value of $f$ (larger resistance effect). Nevertheless, the impact of this change in $x_{D}$ on $K_{l}$ remains limited due to the fact that capillary liquid transport is predominant. The contribution of each transport mode has been investigated in [33, 36] which showed there is a RH transition region (low to high RH values) from water vapour diffusion dominant to liquid transport dominant, depending on the microstructure of the material, its initial moisture content and the RH boundary condition. This transition region is located in higher RH range for more porous material and in lower RH range for less porous material. In this research, for drying of the studied cement pastes at $\mathrm{RH}=53.5 \%$, liquid transport plays the main role.

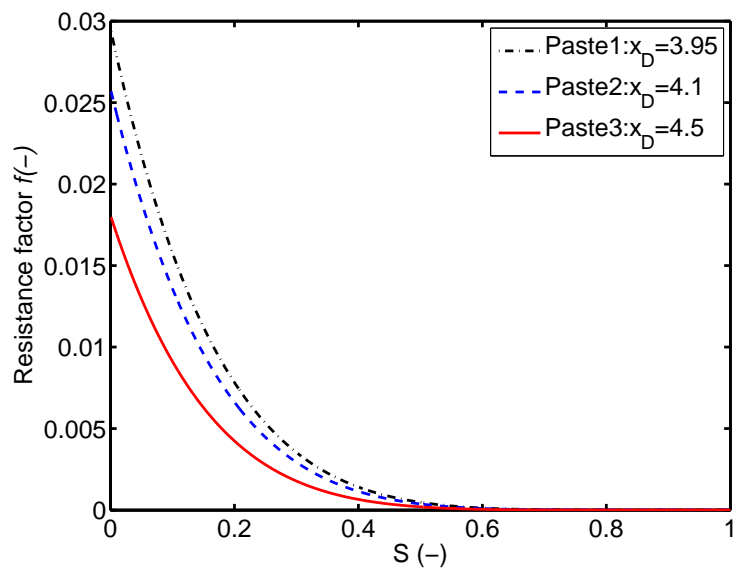

Figure 2: Resistance factor $f$ calculated by Eq. (4) with three different values of $x_{D}$.

We may notice that the adjusted $K_{l}$ and $x_{D}$ by means of the studied "inverse analysis" method is provided for a set of an initial condition (internal degree of saturation after self-desiccation) and drying boundary condition (external RH). If drying occurs for different initial and boundary conditions, results may vary [20]. For example, if Paste1 is exposed to $\mathrm{RH}^{e}=63.2 \%, K_{l}=0.30 \times 10^{-21} \mathrm{~m}^{2}$ is fitted in [20] ( $x_{D}$ fixed at 2.74). In comparison, we find here $K_{l}=0.46 \times 10^{-21} \mathrm{~m}^{2}$ for a $\mathrm{RH}^{e}=53.5 \%$ boundary condition. Those values remains, however, similar due to the level of uncertainty which characterizes the assessment of $K_{l}$ (see Section 5.3 for an illustration of this variability).

\section{Fitting measured apparent diffusion coefficient}

\subsection{Theoretical aspects}

Moisture transport can be modeled using a "diffusion" approach with an apparent diffusion coefficient $D_{a}$ [52, 35] involving water vapour diffusion and liquid water transport. The state variable in this process is a variable representing the moisture content. The liquid water saturation $S$ can be chosen. The equation to solve is a $S$-based form of Richards' equation [53]: 


$$
\frac{\partial S}{\partial t}=\frac{\partial}{\partial x}\left(D_{a} \frac{\partial S}{\partial x}\right)
$$

The apparent diffusion coefficient $D_{a}$ has two components: $D_{a}=D_{l}+D_{v}$, where $D_{l}$ stands for liquid water and $D_{v}$ for water vapour. Using the above-mentioned moisture transport model to interpret Eq. (5), expressions of $D_{l}$ and $D_{v}$ are given as:

$$
\begin{aligned}
D_{l}(S) & =-k_{r l} \frac{K_{l}}{\phi \eta_{l}} \frac{\mathrm{d} P_{c}}{\mathrm{~d} S} \\
D_{v}(S) & =-\left(\frac{M_{v}}{\rho_{l} R T}\right)^{2} D_{v 0} f(S, \phi) \frac{P_{v s} R H}{\phi} \frac{\mathrm{d} P_{c}}{\mathrm{~d} S}
\end{aligned}
$$

where $P_{v s}$ is the saturated water vapour pressure, $M_{v}$ the molar weight of water, $R$ the gas constant and $T$ the absolute temperature.

Similarly to the previous method, $K_{l}$ and $x_{D}$ are two unknown parameters in $D_{a}$. Theoretically, if we know only two values of $D_{a}$, both $K_{l}$ and $x_{D}$ can be calculated by solving Eqs. (10) and (11). Nevertheless, we must ensure that those two values are not chosen in a range of RH where both $D_{l}$ and $D_{v}$ have comparable contribution to $D_{a}$. The contributions of $D_{l}$ and $D_{v}$ to $D_{a}$ according to range of RH have been discussed in [35]. In the high RH range, liquid transport coefficient is prominent whereas vapour diffusion coefficient plays a key role in the low RH range. In fact, there is a very narrow RH range in which both $D_{l}$ and $D_{v}$ have comparable influences on moisture transport (see results in the following Section). This means that effects of $K_{l}$ and $x_{D}$ can be easily separated in most ranges of RH.

\subsection{Experimental data and fitting results}

For the assessment of $D_{a}$, Nilsson has compared various methods [54], including the cup tests and non-steadystate measurements. In the present paper, instead of performing new experiments to determine $D_{a}$ which are generally very time-consuming, we collect data from [35] where measured $D_{a}$ values for the same materials as those studied in Section 3 are provided. For the detailed description of measurements, one can refer to the paper [35]. A brief overview of the principle of measurements is given here. Values for $D_{a}$ were obtained based on sorption isotherms measurements by using thin disks of cement paste $(1-2 \mathrm{~mm})$ with a diameter within the range $70-110 \mathrm{~mm}$. Since the diameter is relatively much larger than the thickness, it can be assumed that moisture loss is mainly from the disk surfaces rather than the circumferential surface. Mass change kinetics between two RH were monitored during the acquisition of water vapour desorption isotherms. The saturated salt solution method was used to maintain the RH constant in the desiccators for each step (RH sensors were put in desiccators to check $\mathrm{RH}$ ). As a matter of fact, if one considers that moisture transport in the material between two small RH steps is governed by diffusion, the value of $D_{a}$ can be indirectly determined by using Eq. (9) to fit the mass change kinetics associated with each measured point of the desorption isotherm. Since a selection of narrow RH steps was used in [35] (10\%), it is acceptable to assume that $D_{a}$ remains almost constant in each RH range. Cup tests with the same materials were also conducted to obtain results for $D_{a}$, which show that the difference with results from sorption isotherm measurements is less than one order of magnitude [35]. On the whole, experimental $D_{a}$ data are available for the desorption for Paste1, Paste2 and Paste3. All available measured curves of $D_{a}$ are fitted by means of Eqs. (10) and (11).

Examples of fitted $D_{a}(R H)$ and $D_{a}(S)$ curves are presented in Figs. 3, 4 and 5 for Paste1, Paste2 and Paste3, respectively. Note that curves in these figures named as "VGMb" will be discussed in Subsection 5.1 The fitted curves capture the trends of the measured data quite well. In the vicinity of $S=0$, all fitted curves drop sharply which is a trend also observed in experiments [55]. Note that $D_{a}(S \rightarrow 0) \approx D_{v}(S \rightarrow 0)$ evolves like $-\mathrm{d} P_{c} / \mathrm{d} S(S \rightarrow 0)$, i.e. $-S^{-2-1 / m}$ (see Eq. 10). It confirms the relevancy of the van Genuchten Equation (6) from an asymptotic point of view.

The calculated values of $K_{l}$ for all the studied materials for the desorption process are provided in Table 3 . Values of $K_{l}$ estimated by the Katz-Thompson model (using the K\&TII model, data are taken from [44]) and by "inverse analysis" of global drying kinetics of specimens exposed to $\mathrm{RH}=53.5 \%$ (see Section 3.2 and Table 2) are compared. Values validated by the current method based on $D_{a}$ assessment are several times smaller than those provided by 


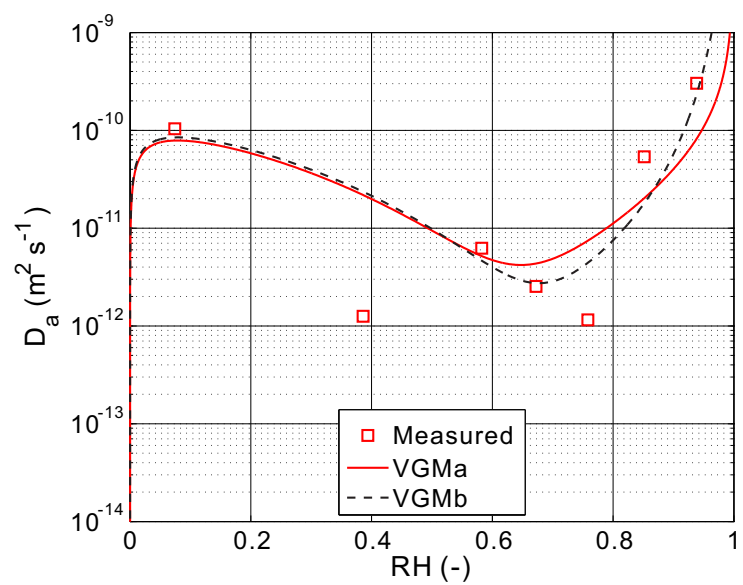

(a) $D_{a}-\mathrm{RH}$

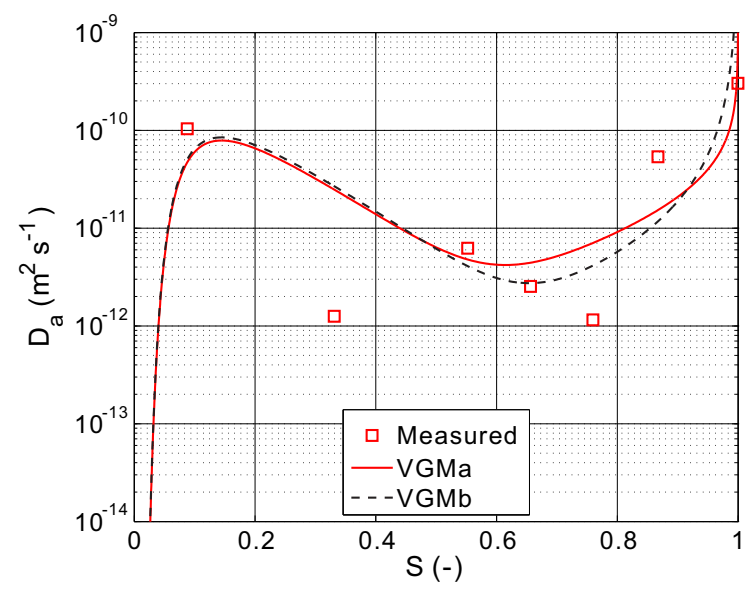

(b) $D_{a}-S$

Figure 3: Fitted $D_{a}$ curves for Paste1 in the desorption process.

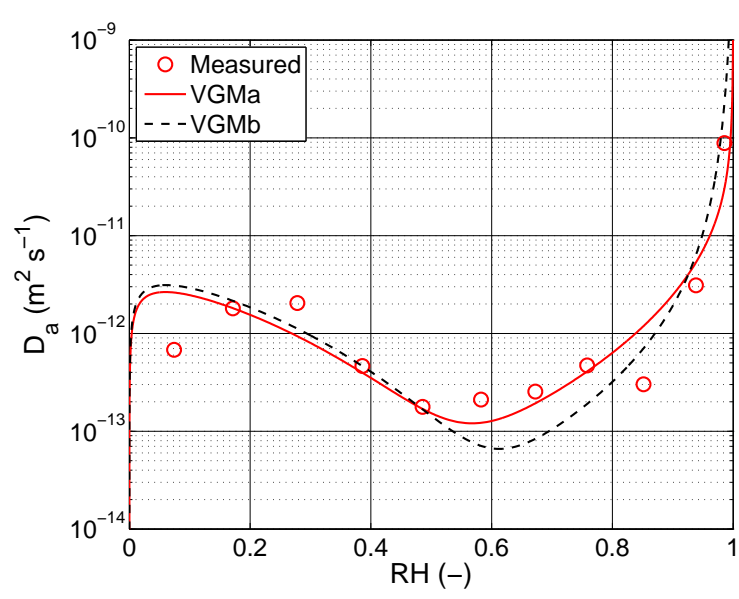

(a) $\mathrm{RH}-D_{a}$

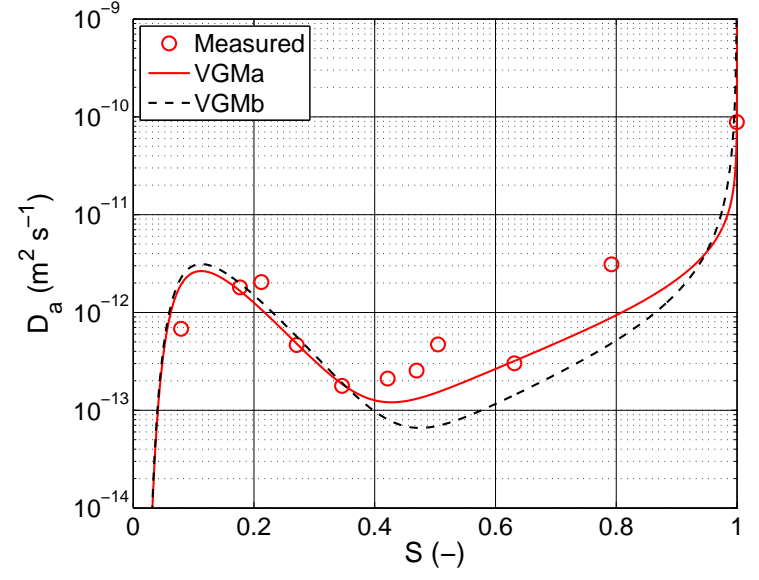

(b) $S-D_{a}$

Figure 4: Fitted $D_{a}$ curves for Paste2 in the desorption process.

the "inverse analysis" method of global drying kinetics, in particular for materials with high w/c. Compared with the large scatter referred in the literature (see the discussion in Section 5.3), differences between these two methods seem acceptable. Note that we confirm that the Katz-Thompson model (K\&TII in the present paper) leads to an overestimation of the permeability as it was expected. Values of permeability assessed by the K\&TI model (using direct measurements of resistivity for the assessment of the formation factor) are proposed in [56] for similar cement pastes made of OPC. Based on mercury intrusion and resistivity data, the assessments provided by Kumar et al. are close to those estimated here by "inverse analysis" of drying kinetics by means of VGMa for the calculation of $k_{r l}$ $\left(\mathrm{w} / \mathrm{c}=0.45: 3 \times 10^{-21} \mathrm{~m}^{2}, \mathrm{w} / \mathrm{c}=0.50: 17 \times 10^{-21} \mathrm{~m}^{2}\right.$ and $\left.\mathrm{w} / \mathrm{c}=0.643: 215 \times 10^{-21} \mathrm{~m}^{2}\right)$.

The fitted $x_{D}$ values in Table 5, denoted as "Without Knudsen effect - VGMa", show that different materials have different values (discussion about the effect of Knudsen diffusion, which can reduce the discrepancy, can be found in section 5). Besides, these values are clearly larger than the one proposed by Millington. We also can see that the $x_{D}$ value for each material shows a good agreement with the "inverse analysis" method (see Table 2), meaning that results from those two methods are quite consistent.

In addition, Figs. 34 and 5 show that several experimental points are far away from the fitting curves of $D_{a}$. The 


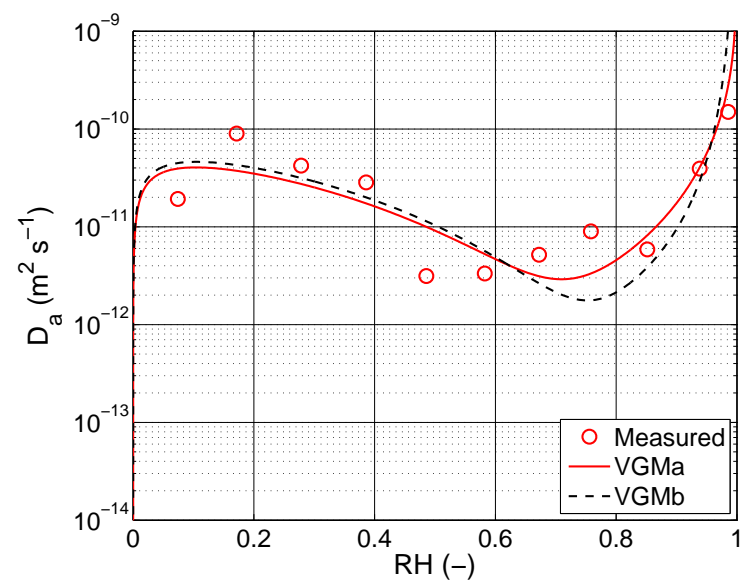

(a) $\mathrm{RH}-D_{a}$

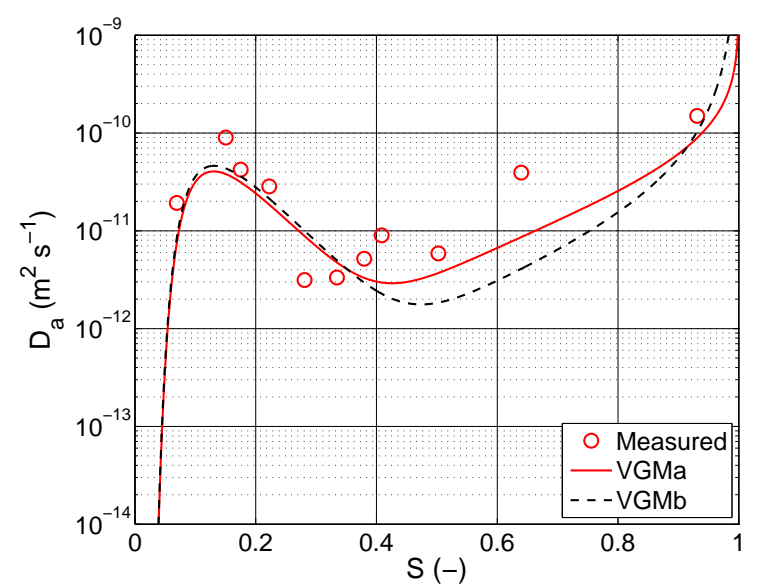

(b) $S-D_{a}$

Figure 5: Fitted $D_{a}$ curves by four models for Paste3 in the desorption process.

fitting precision could to be improved by using a more relevant equation for $D_{a}$. It is also shown that some measured data for certain $\mathrm{RH}$ values are very low, such as $\mathrm{RH}=50 \%$ for Paste2, $\mathrm{RH}=50-60 \%$ for Paste 3 and $\mathrm{RH}=70-80 \%$ for Paste1. As it has been shown in the literature [39], this range of RH (the higher as the w/c is important) corresponds to the threshold pore size which may separate $\mathrm{C}-\mathrm{S}-\mathrm{H}$ pores and capillary pores. According to these figures, this range also corresponds to the transition region between the curve dominated by vapour diffusion and the one by liquid water transport. The moisture equilibrium state might be more difficult to reach and the measurements (i.e. fitting of drying kinetics used for the determination of the sorption isotherm) need longer time compared to other RH ranges [29]. All these reasons result in lower accuracy in this transition region.

Table 3: Comparison of fitted $K_{l}\left(\times 10^{-21} \mathrm{~m}^{2}\right)$ by two methods based on VGMa model with results from the Katz-Thompson model K\&TII.

\begin{tabular}{c|c|c|c}
\hline \hline Materials & Katz-Thompson & "Inverse analysis" $\left(x_{D} \text { adjusted }\right)^{2}$ & Fitting $D_{a}$ : Desorption \\
\hline Paste1 & 37 & 0.51 & 0.17 \\
\hline Paste2 & 71 & 2.15 & 0.30 \\
\hline Paste3 & 231 & 36.0 & 3.01 \\
\hline
\end{tabular}

\section{Discussion}

\subsection{Effect of relative permeability on $K_{l}$}

The relative permeability $k_{r l}$ is generally formulated as a function of liquid water saturation $S$. In early studies, simple equations, such as exponential law [57] and power law [58], were used. They were empirically based. In 1976, following the principle of the "Burdine equation", Mualem developed a simplified model for $k_{r l}$ which is in an integral form (integration of capillary pressure curve) [59]. In 1980, van Genuchten introduced an equation for the capillary pressure curve [40] which was combined with Mualem's integral function of $k_{r l}$ and provided an analytical function for $k_{r l}$ (VGMa model in Section 3). Since then, VGMa model began to be widely accepted and used by researchers [33, [49, 20]. But actually, Mualem also developed a more theoretical model for $k_{r l}$ based on the independent domain theory [60]. Therefore, combining with van Genuchten's equation for sorption isotherm yields the second version of van Genuchten-Mualem (VGM) model for $k_{r l}$. Let's denote this model as VGMb. Compared with VGMa, VGMb

\footnotetext{
${ }^{1}$ Taken from research results by Nguyen [44].

${ }^{2}$ Taken from Table 2
} 
model was derived from the more systematic independent domain theory. It has been used for modelling of mass transport (moisture and ions) in cementitious materials, and rather good results were obtained [44, 49]. However, there is no research which has been done to compare these $k_{r l}$ relations. The present study is devoted to carrying out such comparison. The principle of the independent domain theory has been described in [61] and [20]. Here, only the main equations are briefly provided. According to the principle of independent domain theory, $k_{r l}$ for the main desorption process in VGMb is respectively expressed as [60]:

$$
k_{r l, d}(S)=S^{0.5}[K L-(1-K L) K H]^{2}
$$

where $K L$ and $K H$ are two normalized integral functions calculated from capillary pressure curve. The expressions of these two functions are:

$$
K L=\frac{\int_{P_{c}}^{+\infty} \frac{\mathrm{d} L(S)}{P_{c}}}{\int_{0}^{+\infty} \frac{\mathrm{d} L(S)}{P_{c}}} \quad K H=\frac{\int_{P_{c}}^{+\infty} \frac{\mathrm{d} H(S)}{P_{c}}}{\int_{0}^{+\infty} \frac{\mathrm{d} H(S)}{P_{c}}}
$$

where $L$ and $H$ are two cumulative pore water distribution functions. Their expressions are:

$$
L\left(P_{c}\right)=S_{w}\left(P_{c}\right) \quad H\left(P_{c}\right)=\frac{S_{d}\left(P_{c}\right)-S_{w}\left(P_{c}\right)}{1-S_{w}\left(P_{c}\right)}
$$

where $S_{w}\left(P_{c}\right)$ and $S_{d}\left(P_{c}\right)$ are the saturation from the main adsorption and desorption branches.

It is clear that VGMb model is more sophisticated than VGMa. Indeed, Eqs. (12) to (14) show that the calculation of $k_{r l}$ at a specified RH (or $S$ ) requires integrating the entire sorption curve. This certainly slows down the calculation when this kind model is implemented for moisture transport simulations since the integration cannot be carried out analytically. Moreover, to calculate $k_{r l}$ for the main drying process (Eq. 12), both main desorption and adsorption isotherms must be known; it leads to the fact that hysteresis between desorption and adsorption is involved in the description of $k_{r l}$. These limitations, more sophisticated calculations and requiring more input data, caused that the VGMb model was not widely applied for modelling of moisture transport.

Table 4: Fitted $K_{l}\left(\times 10^{-21} \mathrm{~m}^{2}\right)$ by using VGMb model for the assessment of $k_{r l}$
\begin{tabular}{c|c|c}
\hline Materials & "Inverse analysis" & Fitting $D_{a}$ : Desorption \\
\hline Paste1 & 125 & 23.6 \\
\hline Paste2 & 580 & 28.4 \\
\hline Paste3 & 5500 & 751 \\
\hline
\end{tabular}

The liquid permeability values related to VGMb model are shown in Table 4 for both "inverse analysis" and the fitting of $D_{a}$ method. Those values are much greater than the ones from VGMa model (see Table 3 ). The reason which has already been stated in the literature [29, 36] is that VGMb provides much smaller $k_{r l}$ compared to VGMa. One example for Paste1 in Fig. 6 clearly shows this difference between VGMa and VGMb.

Fitted $D_{a}$ curves by using VGMb model are shown in dashed lines in Figs. 4, 5 and 3 . The shapes of fitted $D_{a}$ curves by VGMa and VGMb are very similar in the range of RH where water vapour diffusion governs moisture transport. For the range of RH dominated by liquid water transport, in spite of the more sophisticated approach used in VGMb and the fact that it accounts for hysteresis in $k_{r l}(S)$ relations, we do not observe that VGMb improves the quality of the fitting of $D_{a}$ curves.

Either for the "inverse analysis" or the fitting of $D_{a}$, the use of VGMb model does not have a profound impact on vapour diffusion. Therefore, there is no need to discuss the fitted $x_{D}$ values according to the choice of $k_{r l}$.

\subsection{Knudsen diffusion effect on $x_{D}$}

When modelling vapour diffusion, it is obvious that Eq. (11) only takes into account ordinary diffusion. As it has been discussed in the literature, ordinary diffusion predominantly occurs in pores between $50 \mathrm{~nm}$ and $10 \mu \mathrm{m}$ (the 


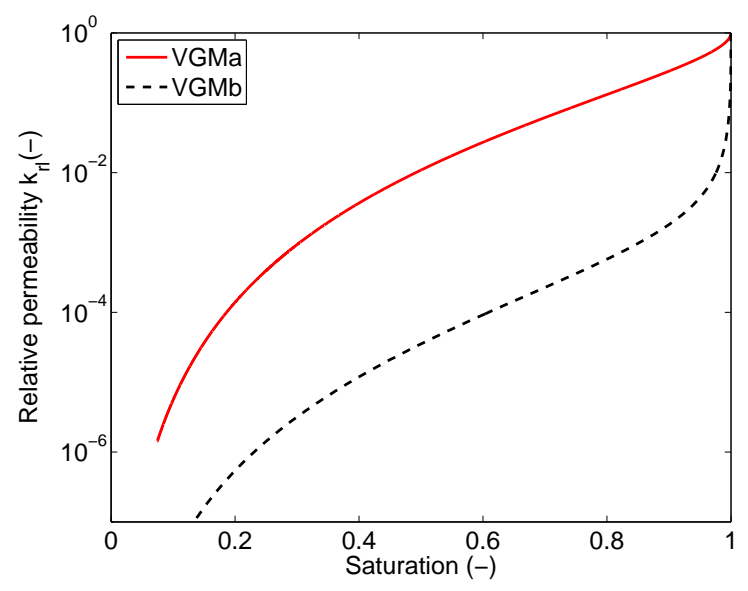

Figure 6: Calculated $k_{r l}$ curves by VGMa and VGMb for Paste1.

typical range of large capillary pores) which corresponds to the range of $\mathrm{RH}>98 \%$ according to the Kelvin-Laplace law. However, in most conditions, vapour diffusion occurs in the range of pores whose size is definitely below $50 \mathrm{~nm}$. In the pore size range 2-50 $\mathrm{nm}$ according to the literature [62], Knudsen diffusion plays a significant role. For this reason, Knudsen effect has to be taken into account in the description of vapour diffusion in this pore size range. This effect is able to slow down the diffusion process due to the collisions between molecules and pore walls [63].

Assuming all pores are independent parallel cylinders, Knudsen diffusion coefficient for a single pore is formulated as [63, 64, 65]:

$$
D_{K, \text { single }}=D_{v 0} \frac{1}{1+\frac{\lambda}{2 r_{K}}}
$$

where $r_{K}$ is the Kelvin pore radius (see Fig. 7) which is the effective radius for Knudsen diffusion. At room temperature (around $293 \mathrm{~K}$ ) and atmospheric pressure $(1 \mathrm{~atm})$, the mean free path $\lambda$ of water molecules is about $80 \mathrm{~nm}$.

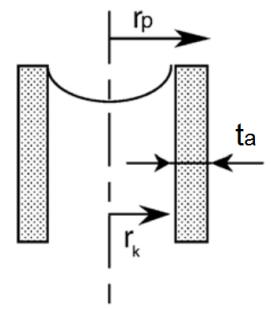

Figure 7: Definition of the Kelvin pore radius $\left(r_{k}\right) . r_{p}$ represents the pore radius and $t_{a}$ the thickness of adsorbed water molecules.

Knudsen diffusion only takes place in pores unfilled by liquid water. Therefore, the macroscopic diffusion coefficient in all parallel pores is obtained by integrating $D_{K, \text { single }}$ over unfilled pores as:

$$
D_{K}=D_{v 0} \int_{r_{K}}^{\infty} \frac{\frac{\mathrm{d} V}{V_{v} \mathrm{~d} r_{p}}}{1+\frac{\lambda}{2\left[r_{p}-t_{a}(R H)\right]}} \mathrm{d} r_{K}
$$


where $\frac{\mathrm{d} V}{V_{v} \mathrm{~d} r_{p}}$ is inferred from the pore size distribution (PSD), which is usually calculated from measured the sorption isotherm. $V_{v}$ is the pore volume for vapour diffusion (volume representing the volume accessible to vapour diffusion, i.e. reduced by the presence of water). The pore radius is given as $r_{p}=r_{K}+t_{a}$ where $t_{a}$ is the thickness of the adsorbed layer of water molecules. Hagymassy et al. [66] firstly published the water vapour $t_{a}$ curve $\left(t_{a} v s\right.$. RH) for non-porous adsorbents based on water vapour adsorption experiments. A generalized expression for the $t_{a}$ curve is:

$$
t_{a}(\mathrm{RH})=\frac{a_{H}}{\left[c_{H}-\log (R H)\right]^{b_{H}}}
$$

where $a_{H}, b_{H}$ and $c_{H}$ are related to the properties of the material. Baroghel-Bouny [39] used Hagymassy's method to calculate the $t_{a}$ curve for cementitious materials and found that it represents a master curve which is used in this paper.

PSD is determined by BJH method which was proposed by Barrett, Joyner and Halenda [67] (see Fig. 8). This method assumes that both capillary and adsorbed water coexist in pores which are treated as cylinders. The radius of the meniscus of capillary water is governed by the Kelvin-Laplace law (see $r_{K}$ in Fig. 77). The thickness of adsorbed layers varies with RH and can be described by $t_{a}$ curve. The BJH method can theoretically calculate the whole pore size distribution corresponding to the range RH 3\%-97\% which is investigated by the saturated salt solutions method. Nonetheless, from a practical point of view, RH 11\% [39] corresponds to a minimum pore size around $r_{p} \approx 0.5 \mathrm{~nm}$ which can be studied by BJH.

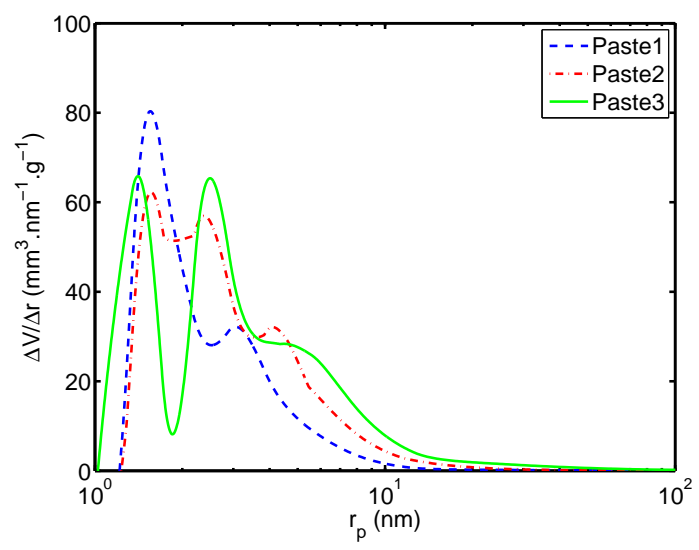

Figure 8: The pore size distribution calculated by BJH method.

Figure 8 shows that PSD for Paste1 has two peaks while PSDs for Paste2 and Paste3 show three peaks. The first peak seems intrinsic since it is observed for all the materials around $r_{p}=1.7 \mathrm{~nm}$. It is supposed to represent the microstructure of the high-density C-S-H formed in the later stage of hydration [39]. The second and third peaks observed for Paste 2 and Paste 3 corresponds to pores in the low-density C-S-H and microcapillarity between lowdensity C-S-H clusters which rapidly grew in the early stage of hydration. The absence of a third peak in case of Paste1 is related to a denser microstructure, and thus fewer low-density C-S-H and capillary pores. These second and third peaks shift to right with the increasing water-to-cement ratio.

The calculated Knudsen effect curves for the studied materials is presented in Fig. 9. As mentioned above, the Knudsen effect can only be calculated for pores larger than $0.5 \mathrm{~nm}$. For pore size below $0.5 \mathrm{~nm}$, the Knudsen effect is considered as the same as that for $r_{p}=0.5 \mathrm{~nm}$. In addition, Fig. 9 shows that $D_{K} / D_{v 0}$ remains nearly constant when RH is below a certain threshold slightly depending on the material. In the range above this RH value, $D_{K} / D_{v 0}$ increases rapidly with RH. For all selected materials, this RH threshold is between $70 \%$ and $80 \%$. Since vapour diffusion is only predominant in the low RH range, the marked increase of $D_{K} / D_{v 0}$ in the high RH range will have a very small influence on the fitting results for $x_{D}$.

To perform the fitting of $D_{a}, D_{K}$ (with the Knudsen effect) is used to replace $D_{v 0}$ in Eq. (11). On the basis of $D_{a}$ curves, the fitted $x_{D}$ values if taking into account the Knudsen effect are compared with the case without the Knudsen 


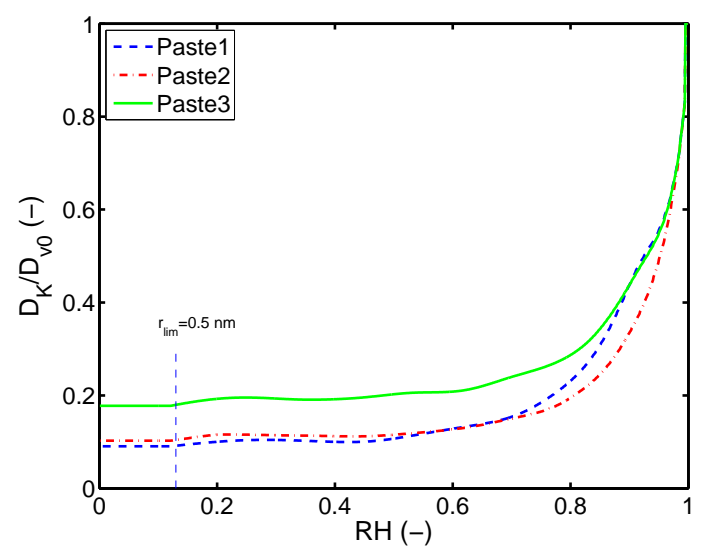

Figure 9: Calculated Knudsen effect on water vapour diffusion.

effect in Table 5. Knudsen effect is only taken into account in $D_{v}$, but since there is a range of RH (even small) where both $D_{v}$ and $D_{l}$ governs $D_{a}$, Knudsen effect leads to slightly different $K_{l}$ values. For the same reason, the use of VGMa or VGMb model for the calculation of $k_{r l}$ does not show significant differences in the determination of $x_{D}$.

Table 5: Fitted $x_{D}$ for the desorption process.

\begin{tabular}{|c|c|c|c|c|c|c|}
\hline \multirow{2}{*}{ Materials } & \multirow{2}{*}{$\begin{array}{l}\text { Millington } \\
\text { [?] }\end{array}$} & \multirow{2}{*}{$\begin{array}{l}\text { Thiéry et } \\
\text { al. [27] }\end{array}$} & \multicolumn{2}{|c|}{ Without Knudsen effect } & \multicolumn{2}{|c|}{ With Knudsen effect } \\
\hline & & & VGMa & VGMb & VGMa & VGMb \\
\hline Paste1 & \multirow{3}{*}{$4 / 3$} & \multirow{3}{*}{2.74} & 2.23 & 2.17 & 0.90 & 0.89 \\
\hline Paste2 & & & 4.26 & 4.10 & 2.39 & 2.22 \\
\hline Paste3 & & & 4.47 & 4.32 & 2.83 & 2.67 \\
\hline
\end{tabular}

An important observation which should be emphasized is that for a given material $x_{D}$ value is much smaller if the Knudsen effect is considered. Knudsen effect decreases the vapour diffusion coefficient, so that a larger value of $f(S, \phi)$ in Eq. (11) is needed. After Knudsen correction, one can see that $x_{D}$ for Paste1 significantly differs from values obtained for Paste2 and Paste 3 which are close. The phenomenon is probably related to the fact that Paste1 with a lower w/c ration has a clearly different microstructure compared to Paste2 and Paste3 as shown in Fig. 8 (two peaks instead of three peaks). Thus, similar $x_{D}$ values for Paste2 and Paste3 is related to the similar PSDs for these two materials.

Note that Kumar et al. [56] performed assessments of the effective diffusion coefficient of water vapour (i.e. $D_{K} f(\phi, S)$ ) for various cement pastes made of OPC by integrating the BJH PSD and taking into account Knudsen diffusion (tortuosity and connectivity effects were determined by electrical measurements). At fixed RH $=50 \%$, Kumar et $a l$. found an effective diffusion coefficient of $0.7 \times 10^{-7} \mathrm{~m}^{2} \cdot \mathrm{s}^{-1}$ and $2.0 \times 10^{-7} \mathrm{~m}^{2} \cdot \mathrm{s}^{-1}$, respectively for $\mathrm{w} / \mathrm{c}=0.45$ and $\mathrm{w} / \mathrm{c}=0.643$. Based on our proposals for $x_{D}$ which encompasses Knudsen effects, calculations lead to $1.5 \times 10^{-7} \mathrm{~m}^{2} \cdot \mathrm{s}^{-1}$ and $7 \times 10^{-7} \mathrm{~m}^{2} \cdot \mathrm{s}^{-1}$, respectively for Paste2 $(\mathrm{w} / \mathrm{c}=0.45)$ and Paste $3(\mathrm{w} / \mathrm{c}=0.6)$. Those results seem quite consistent.

\subsection{Comparison of $K_{l}$ obtained by various methods}

Overall, there are five $K_{l}$ values for each selected material presented in the present paper; they are illustrated in Fig. 10 Values determined by the Katz-Thompson model (K\&TII) are taken from the literature [44] (black bars). The second and third $K_{l}$ values (red bars in Fig. 10 ) are assessed by "inverse analysis" of global drying kinetics. For the last two methods (blue bars), $K_{l}$ values are assessed by fitting measured apparent diffusion coefficient $D_{a}$ in desorption. Results from the two relative permeability models (VGMa and VGMb) are also compared.

Roughly speaking, for each material, $K_{l}$ values indicate that there are two groups. One group with larger values than the Katz-Thompson model corresponds to the approach using VGMb model to calculate $k_{r l}$ [60]. The other group with smaller values corresponds to VGMa to assess $k_{r l}$ [59]. Let's recall that the Katz-Thompson model has been questioned in the literature because it may overestimate $K_{l}$, in particular for cementitious materials with low w/c [21]. 


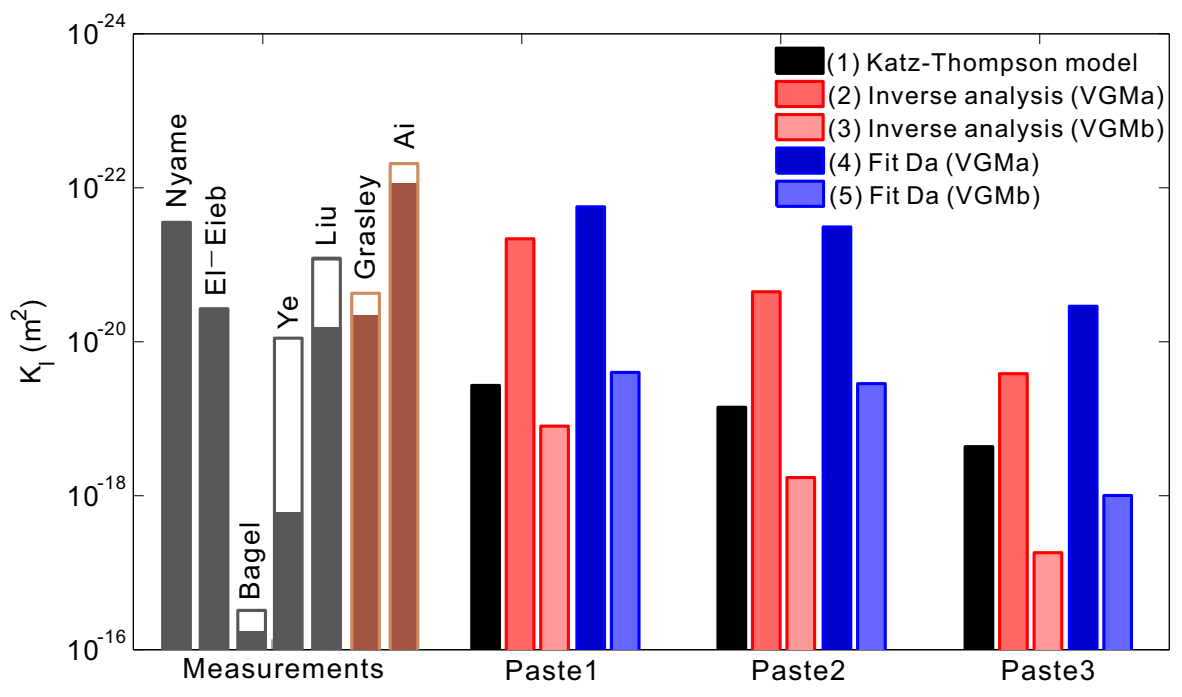

Figure 10: Comparisons of $K_{l}$ values determined by different methods for the studied materials. Short names for Measurements correspond to literature: Nyame = Nyame and Illston (1981) [2], El-Dieb = El-Dieb and Hooton (1995) [4], Bagel = Bagel and Zivica (1997) [5], Ye = Ye (2005) [6], Liu = Liu (2012) [68], Grasley = Grasley et $a l$. (2007) [16],Ai = Ai et al. (2001) [13]. Hollow parts in Measurements represent the range of $K_{l}$ values reported in the literature. Note: A short bar means large $K_{l}$ value.

To further investigate the proposed methods, measured $K_{l}$ values for various cementitious materials are collected from the literature and shown as "Measurements" in Fig. 10. Details for these measurements are provided in Table 6 The first four measurements used the pressure cell to directly measure $K_{l}$. The last two correspond to indirect methods: dynamic pressurization (DP) [16] and thermopermeametry (TPA) [13]. Results for the beam bending method are not shown here because data for mature cementitious materials are not available [7, 8, 9].

Clearly, $K_{l}$ values measured by Bagel and Zivica [5] $(\mathrm{w} / \mathrm{c}=0.4$ or 0.5$)$ are much higher than other measurements. The use of mortars does not explain such a difference which is generally not so high between pastes and mortars [21]. The likely reason is that the specimens were damaged due to the pre-drying at $105^{\circ} \mathrm{C}$. Ye [6] provided measurements for three water-to-cement ratios which show clear differences. The material with w/c $=0.6$ shows $K_{l}$ value about three orders of magnitude higher than the material with $\mathrm{w} / \mathrm{c}=0.4$. This difference is greater than results for the same range of water-to-cement ratios obtained by DP method [16], in which all $K_{l}$ values stay in the order of magnitude of $10^{-21} \mathrm{~m}^{2}$ regardless of pastes or concretes. The same order of magnitude is also observed in Liu's experiments [68], either for materials made of CEM I or CEM V cement (European standard). One may notice that results related to DP method are determined by using Type III cement (American standard) which can lead to a finer microstructure than Type I ordinary cement. Experimental results by El-Dieb and Hooton [4] for mature concrete are also in the same order of magnitude $\left(10^{-21} \mathrm{~m}^{2}\right)$, as well as paste with $\mathrm{w} / \mathrm{c}=0.4$ in Ye's measurements [6]. Results based on thermal expansion of microstructure performed by Ai et al. [13] show lower $K_{l}$ than $10^{-21} \mathrm{~m}^{2}$. As mentioned in the Introduction, TPA method is very sensitive to saturation condition and the presence of air voids. To remove air voids, the paste for TPA test was degassed by vibrating during casting under vacuum which is more effective than the normal vacuum method. The degassing process causes the paste to be much denser than the other pastes. An alternative reason is that adding silica fume creates a finer microstructure. For these reasons, TPA method seems to be more applicable to mature, dense and low w/c materials.

Based on the above discussion and measured data in Table 6 it is possible to conclude that for cementitious materials with water-to-cement ratio between 0.4 and 0.5 the measured liquid permeability $K_{l}$ should be around the order of magnitude of $10^{-21} \mathrm{~m}^{2}$. Following this conclusion, it can be easily seen that the Katz-Thompson model overestimates $K_{l}$ about one or two orders of magnitude. The reviewing of the methods compared in the present study shows that methods related to VGMa provide more reasonable results which are lower than those obtained with the Katz-Thompson model, while methods based on VGMb show much higher values which seem irrelevant. This 
conclusion is also consistent with Kumar et al. results [56] which illustrate slightly higher $K_{l}$ values provided by K\&TI model (see Section 4.2 than assessments performed on the basis of VGMa. On the whole, a global range of $K_{l}$ assessment results would correspond to VGMa, K\&TI, K\&TII and VGMb (highest assessment). The reputation of Katz-Thompson models to lead to an overestimation of permeability confirms that VGMa seems more relevant for the calculation of $k_{r l}$ than VGMb.

Table 6: Collection of measured $K_{l}$ values by different experimental methods from the literature.

\begin{tabular}{|c|c|c|c|c|c|c|c|}
\hline Authors & Method & Cement $^{1}$ & Material & $\bar{w} / \mathrm{c}(\mathrm{w} / \mathrm{b})$ & Age & $\begin{array}{l}\text { Curing } \\
\text { condition }\end{array}$ & $\begin{array}{ll}\text { Liquid } & \text { permeability } \\
\left(\mathrm{m}^{2}\right) & \end{array}$ \\
\hline $\begin{array}{l}\text { Nyame and Ill- } \\
\text { ston (1981) [2] }\end{array}$ & $\begin{array}{l}\text { Hydraulic circuit } \\
\text { pressure cell }\end{array}$ & CEM I & Paste & 0.47 & $\begin{array}{l}20 \\
\text { months }\end{array}$ & Water & $3.0 \times 10^{-22}$ \\
\hline $\begin{array}{l}\text { El-Dieb } \\
\text { and Hooton } \\
(1995)[4]\end{array}$ & $\begin{array}{l}\text { High-pressure } \\
\text { triaxial cell }\end{array}$ & CEM I & Concrete & 0.49 & $\begin{array}{l}14 \\
\text { months }\end{array}$ & Water & $3.72 \times 10^{-21}$ \\
\hline \multirow{2}{*}{$\begin{array}{l}\text { Bagel and Zivica } \\
\text { (1997) [5] }\end{array}$} & \multirow{2}{*}{$\begin{array}{l}\text { Low pressure } \\
\text { cell }\end{array}$} & \multirow{2}{*}{ CEM I } & \multirow{2}{*}{ Mortar } & 0.4 & \multirow{2}{*}{28 days } & \multirow{2}{*}{ Water } & $3.2-5.71 \times 10^{-17}$ \\
\hline & & & & 0.5 & & & $4.17-22.18 \times 10^{-17}$ \\
\hline \multirow{3}{*}{ Ye (2005) [6] } & \multirow{3}{*}{ Pressure cell } & \multirow{3}{*}{ CEM I } & \multirow{3}{*}{ Paste } & 0.4 & \multirow{3}{*}{28 days } & \multirow{3}{*}{ Sealed } & $9 \times 10^{-21}$ \\
\hline & & & & 0.5 & & & $1.33 \times 10^{-19}$ \\
\hline & & & & 0.6 & & & $1.82 \times 10^{-18}$ \\
\hline \multirow{2}{*}{ Liu (2012) [68] } & \multirow{2}{*}{ Pressure cell } & CEM I & \multirow{2}{*}{ Concrete } & 0.43 & \multirow{2}{*}{3 months } & \multirow{2}{*}{ Water } & $1.5-8.88 \times 10^{-21}$ \\
\hline & & CEM V & & 0.39 & & & $0.98-4.21 \times 10^{-21}$ \\
\hline \multirow{4}{*}{$\begin{array}{l}\text { Grasley et al. } \\
\text { (2007) [16 }\end{array}$} & \multirow{4}{*}{$\begin{array}{l}\text { Dynamic } \\
\text { pressurization } \\
\text { (DP) }\end{array}$} & \multirow{4}{*}{ Type III } & \multirow{3}{*}{ Paste } & 0.4 & 14 days & \multirow{4}{*}{ Limewater } & $2 \times 10^{-21}$ \\
\hline & & & & 0.5 & 80 days & & $3 \times 10^{-21}$ \\
\hline & & & & 0.6 & 32 days & & $6.5 \times 10^{-21}$ \\
\hline & & & Concrete & 0.5 & 14 days & & $4.9 \times 10^{-21}$ \\
\hline $\begin{array}{l}\text { Ai et al. } \\
(2001)[13]\end{array}$ & $\begin{array}{l}\text { Thermopermeametry } \\
\text { (TPA) }\end{array}$ & $\begin{array}{l}\text { White OPC } \\
+\quad \text { silica } \\
\text { fume }(6 \%)\end{array}$ & Paste & 0.4 & $\begin{array}{l}36 \\
\text { months }\end{array}$ & Limewater & $2.35-8.65 \times 10^{-23}$ \\
\hline
\end{tabular}

The disadvantage of the two studied indirect methods compared in the present study is obvious: they both need more than one measurement to obtain enough data to determine moisture transport properties $\left(K_{l}\right.$ and $\left.x_{D}\right)$. More specifically, the "inverses analysis" method requires the measured sorption isotherm (capillary pressure curve) as well as the mass loss curve corresponding to a drying experiment of a specimen. Another problem for the "inverses analysis" is that different drying condition (external RH) may also lead to different fitted $K_{l}$ values [44, 29]. To fit measured $D_{a}$ curve $v s$. RH or $S$, one must dispose of this curve which represents a very time-consuming job. That is why, as it has been mentioned in the Introduction, these two methods were not developed for this purpose unless one has enough data in hand. Note that novel experimental devices can help to obtain the required sorption data in a short time, such as using dynamic vapour sorption (DVS) to determine both sorption isotherms and drying kinetics [69, 70, 71, 72]. If a few millimeters thickness specimens can be prepared with the well controlled geometry, the mass loss curve which is necessary for the determination of the sorption isotherm can reach a plateau in several days, which significantly reduce the time compared to the traditional saturated salt solution method.

The collected permeability values (from present research and literature) show usual dispersion. Even the gas permeability, which is easier to measure than water permeability, can dramatically change according samples (even coming from the same batch of concrete [73]). This paper confirms that such variability is also observed in case of the studied inverse analysis methods. It is mainly related to the variability of the input data which are required for the back calculation (capillary pressure curve, porosity, etc.). But if the uncertainties of those input data are managed enough (for instance if the sorption curve is known and not only approximated by the one of an equivalent material), the reliability of the assessment of $K_{l}$ will be increased. Nevertheless, the uncertainties related to the batching, pouring concrete and preparation of specimens will always remain very high leading to an unavoidable lack of confidence in

\footnotetext{
${ }^{1}$ CEM I and CEM V are the OPC material according to European standard - EN 197-1. Type III is the material described in American standard - ASTM C150.
} 
the assessed $K_{l}$ values. Thus, the main objective of future researches would be to weigh the exact role of $K_{l}$ (and its variability) in models used for durability prediction. The reliability framework could be used to reach this objective since it enables to perform a sensitivity analysis.

\section{Conclusion}

The current study has investigated two indirect ways which can be used to infer liquid water permeability $K_{l}$ and parameter $x_{D}$ in the resistance factor of water vapour diffusion based on experimental data and moisture transport modelling. Experimental data collected from literature for three OPC pastes were used for comparison purpose with three different and representative $\mathrm{w} / \mathrm{c}$ ratio $(0.35,0.45$ and 0.6$)$. Back to the two objectives of this paper (stated in the Introduction), we can draw conclusions for each of them.

1 Did we get the same results for moisture transport properties by using those two methods? For the liquid water permeability $K_{l}$, differences can be seen between both methods. $K_{l}$ values from fitting the apparent water vapour diffusivity curve $\left(D_{a} v s\right.$. liquid water saturation $\left.S\right)$ are about 4-10 times smaller these from "inverses analysis" method. But, compared with the variation of measured data referred in the literature, the difference between these two methods is acceptable. For $x_{D}$, both methods provide very close values (without consideration of Knudsen effect). All these results lead to the conclusion that we can get similar results for these two methods even though they need different input data (on one hand, the mass loss curve and, on the other hand, the measured $D_{a}$ vs. $S$ curve).

2 How can other factors affect moisture transport properties? The choice of models for relative permeability $k_{r l}$ can cause significantly different results. Two models for $k_{r l}$ have been studied: an analytical one VGMa (commonly-used in the literature) and a sophisticated one which requires solving numerically (VGMb). Values for $K_{l}$ from VGMb are about two orders of magnitude higher than these for VGMa. The discussion has shown that VGMb model may provide unrealistic results compared with experimental data available in the literature. The consideration of Knudsen effect markedly decreases the vapour diffusion coefficient. Theoretically, this is a most-likely expected trend because Knudsen effect commonly exists in mesopores $(2-50 \mathrm{~nm})$, and this range of pores largely contributes in cementitious materials. The conclusion for this question is that both relative permeability and Knudsen effect can significantly affect the results so that researchers should pay more attention when choosing equations related to those factors.

Beside of the above conclusions, we also found that the calculated mass loss curve (drying) was more sensitive to $K_{l}$ than to $x_{D}$ in the "inverse analysis" method. This finding confirms the previous conclusion made in [36] that moisture transport is mainly in its liquid form in cementitious materials (in a RH range at least above 50\%). For this reason, if one only focuses on the assessment of $K_{l}$, transport equation just with liquid water should be sufficient as already concluded in [33].

Based on a comparison with literature data, we are able to conclude that, for cementitious materials with waterto-cement ratio between 0.4 and 0.5 and made of OPC, the measured liquid permeability $K_{l}$ should be around the order of magnitude of $10^{-21} \mathrm{~m}^{2}$. Following this conclusion, it can be easily seen that the Katz-Thompson model overestimates $K_{l}$ (all the more as the Katz-Thompson model corresponds to the one only based on mercury intrusion data). If reviewing methods compared in the present study, it is pointed out that methods related to VGMa provide more reasonable results while VGMb largely overestimates $K_{l}$. This is the main reason why we recommend VGMa for modelling of moisture transport in cementitious materials, at least for the range of materials that have been investigated in the present paper. In addition to this, there are two more reasons: VGMa [60] model provides is an easy-to-use model and VGMb [60] model is much more sophisticated for its implementation in moisture models.

\section{Acknowledgment}

The research leading to these results has received funding from the European Union Seventh Framework Programme (FP7 / 2007-2013) under grant agreement 264448. 


\section{References}

[1] E. Buckingham, Studies on the movement of soil moisture, Washington, Govt. Print. Off., Washington, DC., 1907.

[2] B. K. Nyame, J. M. Illston, Relationships between permeability and pore structure of hardened cement paste, Magazine of Concrete Research 33 (1981) 139-146.

[3] A. S. El-Dieb, R. D. Hooton, Evaluation of the katz-thompson model for estimating the water permeability of cement-based materials from mercury intrusion porosimetry data, Cement and Concrete Research 24 (1994) 443-455.

[4] A. S. El-Dieb, R. D. Hooton, Water-permeability measurement of high performance concrete using a highpressure triaxial cell, Cement and Concrete Research 25 (1995) 1199-1208.

[5] L. Bagel, V. Zivica, Relationship between pore structure and permeability of hardened cement mortars: on the choice of effective pore structure parameter, Cement and Concrete Research 27 (1997) 1225-1235.

[6] G. Ye, Percolation of capillary pores in hardening cement pastes, Cement and Concrete Research 35 (2005) $167-176$.

[7] G. W. Scherer, Bending of gel beams: method of characterizing mechanical properties and permeability, Journal of Non-Crystalline Solids 142 (1992) 18-35.

[8] G. W. Scherer, Measuring permeability of rigid materials by a beam-bending method: I. theory, Journal of the American Ceramic Society 83 (2000) 2231-2239.

[9] G. W. Scherer, Measuring permeability of rigid materials by a beam-bending method: Iv. transversely isotropic plate, Journal of the American Ceramic Society 87 (2004) 1517-1524.

[10] G. W. Scherer, H. Hdach, J. Phalippou, Thermal expansion of gels: a novel method for measuring permeability, Journal of Non-Crystalline Solids 130 (1991) 157-170, errata, J. Non-Cryst. Solids 194 (1996) 326.

[11] G. W. Scherer, Measuring permeability by the thermal expansion method for rigid or highly permeable gels, Journal of Sol-Gel Science and Technology 3 (1994) 31-40.

[12] G. W. Scherer, Thermal expansion kinetics: method to measure permeability of cementitious materials: I, theory, Journal of the American Ceramic Society 83 (2000) 2753-2761, erratum, J. Am. Ceram. Soc. 87 (8) (2004) 1609 -1610 .

[13] H. Ai, J. F. Young, G. W. Scherer, Thermal expansion kinetics: Method to measure permeability of cementitious materials: Ii, application to hardened cement pastes, J. Am. Ceram. Soc. 84 (2001) 385-391.

[14] M. Zalzale, Water dynamics in cement paste: insights from lattice boltzmann modelling, Ph.D. thesis, Ecole Polytechinique Federale de Lausanne (EPFL) (2014).

[15] G. W. Scherer, Dynamic pressurization method for measuring permeability and modulus: I. theory, Materials and Structures 39 (2006) 1041-1057.

[16] Z. C. Grasley, G. W. Scherer, D. A. Lange, J. J. Valenza, Dynamic pressurization method for measuring permeability and modulus: II. cementitious materials, Materials and Structures 40 (2007) 711-721.

[17] A. H. Thompson, A. J. Katz, C. E. Krohn, The microgeometry and transport properties of sedimentary rock, Advances in Physics 36 (1987) 625-694.

[18] V. Baroghel-Bouny, K. Kinomura, M. Thiéry, S. Moscardelli, Easy assessment of durability indicators for concretes with high volume of scms, Cement and Concrete Composites 33 (2011) 832-847. 
[19] J. Zhang, G. W. Scherer, Comparison of methods for arresting hydration of cement, Cement and Concrete Research 41 (2011) 1024-1036.

[20] Z. Zhang, M. Thiery, V. Baroghel-Bouny, Numerical modelling of moisture transfers with hysteresis within cementitious materials: Verification and investigation of the effects of repeated wetting-drying boundary conditions, Cement and Concrete Research 68 (2015) 10-23.

[21] P. Halamickova, R. J. Detwiler, D. P. Bentz, E. J. Garboczi, Water permeability and chloride ion diffusion in portland cement mortars: Relationship to sand content and critical pore diameter, Cement and Concrete Research 25 (1995) 790-802.

[22] D. L. Johnson, J. Koplik, L. M. Schwartz, New pore-size parameter characterizing transport in porous media, Phys. Rev. Lett. 57 (1986) 2564-2567.

[23] J. Crank, G. Park, Diffusion in Polymers, Academic, New York, 1986.

[24] N. Vahdat, V. Sullivan, Estimation of permeation rate of chemicals through elastometric materials, Journal of Applied Polymer Science 79 (2001) 1265-1274.

[25] H. L. Frisch', The time lag in diffusion, J. Phys. Chem. 61 (1957) 93-95.

[26] A. Z. Akcasu, Temperature and concentration dependence of diffusion coefficient in dilute solutions, Polymer 22 (1981) 1169-1180.

[27] M. Thiery, V. Baroghel-Bouny, N. Bourneton, G. Villain, C. Stéfani, Modélisation du séchage des bétons Analyse des différents modes de transfert hydrique, Revue européenne de génie civil 11 (2007) 541-577.

[28] Z. Bažant, L. Najjar, Nonlinear water diffusion in nonsaturated concrete, Materials and structures 5 (1) (1972) 3-20.

[29] Z. Zhang, Modelling of sorption hysteresis and its effect on moisture transport within cementitious materials Ph.D. thesis, Université Paris-Est (2014).

URL https://tel.archives-ouvertes.fr/tel-01127302

[30] J. Bear, Dynamics of Fluids in Porous Media, Elsevier Publishing Co., New York, 1972.

[31] O. Coussy, Mechanics of porous continua, Wiley, New York, 1995.

[32] O. Coussy, V. Baroghel-Bouny, P. Dangla, M. Mainguy, Assessment of the water permeability of concretes from their mass loss during drying (in French), in: V. Baroghel-Bouny (Ed.), Transferts dans les bétons et durabilité, Special issue of Revue Française de Génie Civil, vol. 5, Hermès Science Publications, Paris, 2001, pp. 269-284.

[33] M. Mainguy, O. Coussy, V. Baroghel-Bouny, Role of air pressure in drying of weakly permeable materials, Journal of Engineering Mechanics 127 (2001) 582-592.

[34] V. Baroghel-Bouny, M. Thiéry, F. Barberon, O. Coussy, G. Villain, Assessment of transport properties of cementitious materials. A major challenge as regards durability?, Revue European de Genie Civil 11 (2007) 671-696.

[35] V. Baroghel-Bouny, Water vapour sorption experiments on hardened cementitious materials. Part II: Essential tool for assessment of transport properties and for durability prediction, Cement and Concrete Research 37 (2007) 438-454.

[36] Z. Zhang, M. Thiéry, V. Baroghel-Bouny, Analysis of moisture transport in cementitious materials and modelling of drying-wetting cycles, in: International Conference: Numerical Modeling Strategies for Sustainable Concrete Structures, The French Association of Civil Engineering (AFGC), Aix-en-Provence, France, 2012, pp. I-5 FP 277.

[37] O. Coussy, Mechanics and physics of porous solids, John Wiley \& Sons, Ltd, United Kingdom, 2010. 
[38] O. Coussy, M. Thiéry, Asymptotic, in: Poro-Mechanics IV, Ed. by Hoe I. Ling and Andrew Smyth, DEStech Publications, Inc., Lancaster, USA, 2009, pp. 384-389.

[39] V. Baroghel-Bouny, Water vapour sorption experiments on hardened cementitious materials. Part I: Essential tool for analysis of hygral behaviour and its relation to pore structure, Cement and Concrete Research 37 (3) (2007) $414-437$.

[40] M. T. van Genuchten, A closed-form equation for predicting the hydraulic conductivity of unsaturated soils, Soil Science Society of America Journal 44 (1980) 892-898.

[41] Z. Zhang, M. Thiery, V. Baroghel-Bouny, A review and statistical study of existing hysteresis models for cementitious materials, Cement and Concrete Research 57 (2014) 44-60.

[42] J. P. Monlouis-Bonnaire, J. Verdier, B. Perrin, Prediction of the relative permeability to gas flow of cement-based materials, Cement and Concrete Research 34 (2004) 737-744.

[43] C. Zhou, Predicting water permeability and relative gas permeability of unsaturated cement-based material from hydraulic diffusivity, Cement and Concrete Research 58 (2014) 143-151.

[44] M. T. Nguyen, Modélisation des couplages entre hydratation et dessiccation des matériaux cimentaires à l'issue du décoffrage, Ph.D. thesis, ENPC (September 2009).

[45] S. D. Pont, F. Meftah, B. A. Schrefler, Modeling concrete under severe conditions as a multiphase material, Nuclear Engineering and Design 241 (2011) 562-572.

[46] M. Azenha, K. Maekawa, T. Ishida, R. Faria, Drying induced moisture losses from mortar to the environment. Part II: numerical implementation, Materials and Structures 40 (2007) 813-825.

[47] M. Thiéry, P. Belin, V. Baroghel-Bouny, M. D. Nguyen, Modelling of isothermal drying process in cementitious materials - Analysis of the moisture transfer and proposal of simplified approaches, in: Proceedings of 3rd International Conference on Coupled T-H-M-C Processes in Geo-systems, Polytech Lille, France, 2008, pp. $571-581$.

[48] T. Nguyena, J. Petković, P. Dangla, V. Baroghel-Bouny, Modelling of coupled ion and moisture transport in porous building materials, Construction and Building Materials 22 (2008) 2185-2195.

[49] V. Baroghel-Bouny, M. Thiéry, X. Wang, Modelling of isothermal coupled moisture-ion transport in cementitious materials, Cement and Concrete Research 41 (2011) 828-841.

[50] G. Villain, M. Thiery, Gammadensimetry: A method to determine drying and carbonation profiles in concrete, NDT \& E International 39 (2006) 328-337.

[51] V. Baroghel-Bouny, M. Thiéry, X. Wang, Modelling of isothermal coupled moisture-ion transport in cementitious materials, Cement and Concrete Research 41 (2011) 828-841.

[52] J. Carmeliet, S. Roels, Determination of the isothermal moisture transport properties of porous building materials, Journal of Thermal Envelope and Building Science 24 (2001) 183-210.

[53] M. A. Celia, E. T. Bououtas, R. L. Zarba, A general mass-conservative numerical solution for the unsaturated flow equation, Water Resources Research 26 (1990) 1483-1496.

[54] L.-O.Nilsson, A comparison between different methods to determine moisture transport properties of cementitious materials, Tech. rep., Report TVBM 3168, Division of Building Materials, Lund Institute of Technology/Lund University, Sweden (2013).

[55] S. Zamani, R. Kowalczyk, P. J. McDonald, The relative humidity dependence of the permeability of cement paste measured using garfield nmr profiling, Cement and Concrete Research 57 (2014) 88-94. 
[56] A. Kumar, S. Ketel, K. Vance, T. Oey, N. Neithalath, G. Sant, Water vapor sorption in cementitious materials-measurement, modeling and interpretation, Transport in porous media 103 (1) (2014) 69-98.

[57] M. Kutilek, J. Valentova, Sorptivity approximations, Transp. Porous Media 1 (1986) 57-62.

[58] G. Campbell, A simple method for determining unsaturated conductivity from moisture retention data, Soil Sci. 117 (1974) 311-314.

[59] Y. Mualem, A new model for predicting the hydraulic conductivity of unsaturated porous media, Water Resources Research 12 (1976) 513-522.

[60] Y. Mualem, Hysteretical models for prediction fo the hydraulic conductivity of unsaturated porou media, Water Resources Research 12 (1976) 1248-1254.

[61] Y. Mualem, A conceptual model of hysteresis, Water Resources Research 10 (3) (1974) 514-520.

[62] K. Malek, M. O. Coppens, Knudsen self- and Fickian diffusion in rough nanoporous media, Journal of Chemical Physics 119 (2003) 2801-2811.

[63] J.-F. Daïan, Condensation and isothermal water transfer in cement mortar. Part I: pore size distribution, equilibrium water condensation and imbibition, Transport in Porous Media 3 (1988) 563-589.

[64] K. Gertis, U. Wolfseher, Isothermer gastrasnport in porosen stoffen aus gas kinetischer sicht, Deustcher Ausschuss fur Stahlbeton (1976) 36-62.

[65] V. Baroghel-Bouny, Characterization of cement pastes and concretes-methods, analysis, interpretations (in French), Ph.D. thesis, ENPC (LCPC Publ., Paris) (1994).

[66] J. Hagymassy, S. Brunauer, R. S. Mikhail, Pore structure analysis by water vapor adsorption, I. t-curves for water vapor, Journal of Colloid Interface Science 127 (1969) 485-491.

[67] E. P. Barrett, L. G. Joyner, P. P. Halenda, The determination of pore volume and area distributions in porous substances. I. Computations form nitrogen isotherms, Journal of the American Chemical Society 71 (1951) 373-380.

[68] J. Liu, Experimental study on gas and water relative permeability of cementitious materials and numerical simulation of water transport of concrete (in French), Ph.D. thesis, Ecole Centrale de Lille (2012).

[69] M. Janz, B. F. Johannesson, Measurement of the moisture storage capacity using sorption balance and pressure extractors., Journal of Thermal Envelope and Building Science (2001) 316-334.

[70] L. Wadsö, K. Svennberg, A. Dueck, An experimentally simple method for measuring sorption isotherms, Drying Technology: An International Journal (2004) 2427-2440.

[71] M. Wu, B. Johannesson, M. Geiker, A study of the water vapor sorption isotherms of hardened cement pastes: Possible pore structure changes at low relative humidity and the impact of temperature on isotherms, Cement and Concrete Research (2014) 97-105.

[72] M. Saeidpour, L. Wadsö, Moisture equilibrium of cement based materials containing slag or silica fume and exposed to repeated sorption cycles, Cement and Concrete Research 69 (2015) 88-95.

[73] A. Aït-Mokhtar, R. Belarbi, F. Benboudjema, N. Burlion, B. Capra, M. Carcasses, J.-B. Colliat, F. Cussigh, F. Deby, F. Jacquemot, et al., Experimental investigation of the variability of concrete durability properties, Cement and concrete research 45 (2013) 21-36. 